\title{
The risk of burn injury during long-term oxygen therapy: a 17-year longitudinal national study in Sweden
}

\author{
Hanan A Tanash' \\ Fredrik Huss ${ }^{2,3}$ \\ Magnus Ekström ${ }^{4}$ \\ 'Department of Respiratory Medicine \\ and Allergology, Skåne University \\ Hospital, Lund University, Lund, \\ ${ }^{2}$ Department of Surgical Sciences, \\ Plastic Surgery, Uppsala University, \\ ${ }^{3}$ Burn Center, Department of \\ Plastic and Maxillofacial Surgery, \\ University Hospital of Uppsala, \\ Uppsala, ${ }^{4}$ Department of Clinical \\ Sciences, Division of Respiratory \\ Medicine \& Allergology, Lund \\ University, Lund, Sweden
}

This article was published in the following Dove Press journal: International Journal of COPD

13 November 2015

Number of times this article has been viewed

Background: Long-term oxygen therapy (LTOT) improves the survival time in hypoxemic chronic obstructive pulmonary disease. Despite warnings about potential dangers, a considerable number of patients continue to smoke while on LTOT. The incidence of burn injuries related to LTOT is unknown. The aim of this study was to estimate the rate of burn injury requiring health care contact during LTOT.

Methods: Prospective, population-based, consecutive cohort study of people starting LTOT from any cause between January 1, 1992 and December 31, 2009 in the Swedish National Register of Respiratory Failure (Swedevox).

Results: In total, 12,497 patients (53\% women) were included. The mean (standard deviation) age was $72 \pm 9$ years. The main reasons for starting LTOT were chronic obstructive pulmonary disease (75\%) and pulmonary fibrosis (15\%). Only 269 (2\%) were active smokers when LTOT was initiated. The median follow-up time to event was 1.5 years (interquartile range, $0.55-3.1$ ). In total, 17 patients had a diagnosed burn injury during 27,890 person-years of LTOT. The rate of burn injury was 61 (95\% confidence interval, 36-98) per 100,000 person-years. There was no statistically significant difference in the rate of burn injury between ever-smokers and never-smokers, or between men and women.

Conclusion: The rate of burn injuries in patients on LTOT seems to be low in Sweden. The strict requirements in Sweden for smoking cessation before LTOT initiation may contribute to this finding.

Keywords: respiratory failure, oxygen, fire, burn, mortality, smoking

\section{Introduction}

Long-term oxygen therapy (LTOT) improves the survival time in chronic obstructive pulmonary disease (COPD) complicated by severe hypoxemia. ${ }^{1,2}$ The indication for LTOT has in many clinical settings expanded from hypoxic COPD to other hypoxic conditions such as hypoxemic pulmonary fibrosis and congestive heart failure. More than a million people are on LTOT in the USA alone. ${ }^{3}$ The incidence of LTOT has increased in recent decades and is projected to increase further, especially in women. ${ }^{4}$

Smoking and the need for LTOT are closely linked. An estimated 90\% of COPD is attributable to smoking-related lung damage and most patients starting LTOT are ever-smokers. ${ }^{5,6}$ Smoking cessation is the most effective treatment to slow the progress of COPD. ${ }^{7}$ Unfortunately, many patients find it difficult to quit smoking. It is estimated that among patients on LTOT, as many as $20 \%-40 \%$ continue to smoke. ${ }^{8,9}$

LTOT may increase the risk of fire incidents and burn injuries in relation to smoking and contact with sparks or open flames. An oxygen-enriched atmosphere increases the risk of ignition at lower ambient temperatures and may cause a fierce and explosive
Correspondence: Hanan A Tanash Department of Respiratory Medicine and Allergology, Skåne University Hospital, Lund University, Inga Marie Nilssons gata 46, S-205 02, Malmö, Sweden

Email hanan.tanash@med.lu.se 
combustion. Smoking is cited as a contraindication for prescribing LTOT in countries including Sweden, mainly due to a perceived increased risk of fire and burn injury. ${ }^{4,10}$ In other settings, smokers in need of the therapy are eligible for LTOT after receiving information and risk-reducing interventions. ${ }^{9,11}$

The knowledge about the risk of burn injury during LTOT is limited. The few publications on the risks of continued smoking while on LTOT were mainly retrospective reviews and case series of patients treated at specialized burn centers. ${ }^{12-14}$ LTOT-related burn injuries were probably underestimated because less severe injuries were not captured and because data on the fact that LTOT was in use may have been lacking in some medical records. LTOT has been linked to an estimated 182 home fires annually in the USA, and smoking while using LTOT accounted for more than $70 \%$ of these incidents. ${ }^{15}$ A retrospective study of 1,199 patients admitted to a burn unit reported 17 burn injuries between 1999 and 2008 related to smoking while on LTOT. ${ }^{16}$ Longitudinal population-based data on the incidence and determinants of burn injury during LTOT are lacking.

Sweden offers unique opportunities to study outcomes and events during LTOT. The National Register of Respiratory Failure (Swedevox) prospectively includes patients starting LTOT in Sweden since 1987 and can be cross-linked with high coverage national health care registers using Swedish personal identity numbers. ${ }^{17}$

The aim of this study was to estimate the incidence of burn injury that required contact with a health care professional or center during LTOT and explore clinical factors (including smoking status) associated with increased risk of burn injury.

\section{Methods}

This was a prospective, population-based, consecutive cohort study of people starting LTOT due to any cause between January 1, 1992 and December 31, 2009 in the national Swedevox Register. No patients were excluded.

Swedevox covers approximately $85 \%$ of all adults on LTOT in Sweden since January 1, 1987. The register has been detailed elsewhere. ${ }^{4}$ The LTOT was given according to guidelines from the Swedish Society of Chest Medicine. ${ }^{18}$ The Swedish indications for LTOT are in line with international guidelines. ${ }^{17}$ Contraindications are continued smoking and use of gas stoves or open fireplaces, which have been applied since 1987. LTOT is discouraged in patients who do not comply with the requirements of the therapy or are at high risk of falls.

Data on covariates were obtained from Swedevox regarding age, sex, smoking status (never, former, or active smoking), physician-diagnosed disease that was the main reason for starting LTOT, blood gases, the date and reason for LTOT withdrawal, and the World Health Organization (WHO) performance status at the time of initiating LTOT (baseline). WHO performance status is used to quantify the functional status of patients between 0 (fully active) and 4 (completely bedridden). ${ }^{19}$

Data on diagnoses, external causes, procedures, and mortality were obtained from the National Patient Register for inpatient and outpatient care, and were coded according to the 9th (before 1996) and the 10th revisions of the WHO International Classification of Disease. The register covers more than $99 \%$ of all hospitalizations since 1987 and approximately $80 \%$ of all hospital-based outpatient care since 2001 in Sweden. ${ }^{20}$ Vital status was obtained from the National Causes of Death Register. Patients were followed prospectively from the date of starting LTOT (baseline) until the first of the following occurred: LTOT withdrawal, death, or study end (December 31, 2009).

The primary endpoint was burn injury during follow-up. Burn injury was assessed through a two-step process. First, all International Classification of Disease codes (diagnoses, external causes, and procedures) in the National Patient Register and the National Causes of Death Register were screened and categorized as possible burn injury using the definition in Table 1. Second, the study database was examined by a senior plastic surgeon (FH) specialized in burn care who manually evaluated all International Classification of Disease codes from the health care contacts with a diagnosis of possible burn injury. Each event was categorized either as burn injury (subcategorized as skin or inhalational injury) or no burn injury. The categorization was cross-validated by a second author (ME). Patients with uncertain codes were categorized through consensus discussion (FH and ME) or, if still unclear, were categorized as having a burn injury. The assessment and categorization were blinded to all patient covariates besides the diagnoses, external cause, and procedural codes. Death related to burn injury was defined as the presence of a burn-related cause of death or any death occurring within 30 days after a burn injury.

The study was approved by the Lund University Research Ethics Committee (157/2007 and 350/2008), the Swedish National Board of Health and Welfare, and the Data Inspection Board. According to Swedish research legislation and the ethics approval, individual patient consent was not required for this analysis.

\section{Statistical analysis}

Baseline characteristics were tabulated using descriptive statistics. The rate of burn injuries was calculated as the 
Table I Definition of possible burn injury

\begin{tabular}{lll}
\hline Data item & ICD-9 codes & ICD-I0 codes \\
\hline Diagnosis & 906; 940-949 & HI6; J68; L55.0-L55.2; L55.8; L55.9; T20-T32; T4I.5; T59.8; T59.9; T95.0; Y48.5 \\
Exposure & E890; E899; E837; E868; E9I9; E869.8; & X00-X09; XI4; X47; X49; X69; X76; X77; X88; X97; X98; YI7; YI9; Y25-Y27; \\
& E869.9; E958.I; E929.4; E923.2; E968.0 & W36; ZZA \\
Procedure & 8902; 8903; 8909; 8999; 8930; 8960; 896I & QAB; QAD; QAE; QAC00; QAFI0; QAF99; QBB; QBD; QBE; QBC00; QBFI0; \\
& & QBF99; QCB; QCD; QCE; QCC00; QCFI0; QCF99; QDB; QDD; QDE; \\
& & QDC00; QDFI0; QDF99; QXB; QXD; QXE; QXC00; QXFI0; QXF99
\end{tabular}

Note: Definition of possible burn injury used for screening of diagnoses, exposures, and procedure codes in the National Patient Register for inpatient and outpatient care and the National Causes of Death Register (diagnoses only).

Abbreviation: ICD, International Classification of Disease.

number of first burn injuries divided by the time at risk of first burn injury. Time at risk was defined as person-years from starting LTOT until date of first burn injury diagnosis, LTOT withdrawal, death, or study end (December 31, 2009), whichever came first. Stratified analysis of the rate of burn injury was performed according to possible risk factors: smoking status, sex, WHO performance status, underlying disease, and year of starting LTOT. We calculated $95 \%$ confidence intervals for all estimates. Statistical analyses were performed with the Statistical Package for the Social Sciences (SPSS), version 22.0 (IBM Corporation, Armonk, NY, USA).

\section{Results}

\section{Patients}

A total of 12,497 patients (53\% women) started LTOT between 1992 and 2009 and were included in the study. Baseline characteristics are shown in Table 2. The mean age was $72 \pm$ (standard deviation) 9 years. The main reasons for starting LTOT were COPD (75\%) and pulmonary fibrosis (15\%). The median follow-up time for risk of burn injury was 1.5 years (interquartile range, $0.44-3.1$ ).

Smoking status at baseline was available in 12,073 patients $(97 \%)$. The majority of patients were former smokers and only $269(2 \%)$ were active smokers when LTOT was initiated. The main indication for LTOT in active smokers was COPD $(n=245 ; 91 \%)$. The rate of active smokers among patients starting LTOT decreased after 2005 from 15-20 patients/year to 10-12 patients/ year. Relapse into smoking and/or insufficient compliance were the documented reasons for the withdrawal of LTOT in 61 patients $(0.5 \%)$.

\section{Burn injuries during LTOT}

The mean rate of burn injuries stratified by sex, smoking status, WHO performance status, underlying disease, and year of starting LTOT is shown in Table 3. In total, 17 patients had a diagnosed first burn injury during 27,890 person-years on LTOT. The rate of burn injury was 61 (95\% confidence interval, 36-98) per 100,000 person-years on LTOT. Of the 17 burn injuries, five were inhalation injuries and 12 skin injuries (three full thickness burns and one deep dermal burn; six [50\%] were facial burns). The observed rate of burn injury tended to be higher in women than in men and higher in people starting LTOT after 1998 than earlier (Table 3), but the difference was not significant: rate ratio 0.43 (95\% confidence interval 0.10-1.45) for men versus women and 0.38 (95\% confidence interval 0.07-1.43) for start before versus after 1998, respectively. Rates were similar for ever-smokers and never-smokers and when stratified by performance status and underlying diagnosis (COPD vs other).

Table 2 Characteristics of I 2,497 patients starting LTOT in Sweden, 1992-2009

\begin{tabular}{|c|c|}
\hline Characteristic & $N=12,497$ \\
\hline Female, $\%$ & 53 \\
\hline $\mathrm{PaO}_{2}$ on air, $\mathrm{kPa}(\mathrm{mmHg})$, mean $\pm \mathrm{SD}, \mathrm{n}(\%)$ & $6.6 \pm 0.9(49.5 \pm 7)$ \\
\hline $\mathrm{PaCO}_{2}$ on air, $\mathrm{kPa}(\mathrm{mmHg})$, mean $\pm \mathrm{SD}, \mathrm{n}(\%)$ & $6.2 \pm 1.3(46.5 \pm 10)$ \\
\hline $\mathrm{PaO}_{2}$ on oxygen, $\mathrm{kPa}(\mathrm{mmHg})$, mean $\pm \mathrm{SD}, \mathrm{n}(\%)$ & $8.9 \pm 1.2(66.8 \pm 9)$ \\
\hline $\mathrm{PaCO}_{2}$ on oxygen, $\mathrm{kPa}(\mathrm{mmHg})$, mean $\pm \mathrm{SD}, \mathrm{n}(\%)$ & $6.5 \pm 1.3(48.8 \pm 10)$ \\
\hline $\mathrm{FEV}_{1}, \mathrm{~L}$, mean $\pm \mathrm{SD}$ & $0.9 \pm 0.6$ \\
\hline FVC, L, mean \pm SD & $1.8 \pm 0.8$ \\
\hline Oxygen dose, $\mathrm{L} / \mathrm{min}$, mean $\pm \mathrm{SD}$ & $1.7 \pm 1.1$ \\
\hline Oxygen duration, $\mathrm{h} / 24$ hours, mean $\pm \mathrm{SD}$ & $18 \pm 3$ \\
\hline \multicolumn{2}{|l|}{ Smoking status, \% } \\
\hline Never & 14 \\
\hline Past & 81 \\
\hline Current & 2 \\
\hline Missing & 3 \\
\hline \multicolumn{2}{|l|}{ WHO performance status, $\%$} \\
\hline $0-1$ & 46 \\
\hline $2-4$ & 47 \\
\hline Missing & 7 \\
\hline Burn injuries that occurred before LTOT start & 53 \\
\hline
\end{tabular}

Abbreviations: LTOT, long-term oxygen therapy; $\mathrm{FEV}_{1}$, forced expiratory volume in I second; FVC, forced vital capacity; $\mathrm{PaCO}_{2}$, arterial partial pressure of carbon dioxide; $\mathrm{PaO}_{2}$, arterial partial pressure of oxygen; WHO, World Health Organization. 
Table 3 Burn injuries during LTOT in 12,497 patients

\begin{tabular}{|c|c|c|c|}
\hline Patient group & Burn injuries, $\mathbf{n}$ & Total person-years of LTOT & $\begin{array}{l}\text { Rate }(95 \% \mathrm{Cl}) \text { per } \\
100,000 \text { person-years }\end{array}$ \\
\hline Overall & 17 & 27,890 & $61(36-98)$ \\
\hline Men & 4 & 11,674 & $34(9-88)$ \\
\hline Women & 13 & 16,215 & $80(43-137)$ \\
\hline Ever-smokers & 14 & 23,268 & $60(33-101)$ \\
\hline Never-smokers & 3 & 3,373 & $89(18-260)$ \\
\hline \multicolumn{4}{|c|}{ WHO performance status } \\
\hline $0-1$ & 9 & 15,652 & $57(26-109)$ \\
\hline $2-4$ & 8 & 10,452 & $76(33-151)$ \\
\hline \multicolumn{4}{|l|}{ Main diagnoses } \\
\hline COPD & 14 & 22,794 & $61(34-103)$ \\
\hline Others & 3 & 5,096 & $59(12-172)$ \\
\hline \multicolumn{4}{|l|}{ LTOT start year } \\
\hline Before 1998 & 3 & 10,060 & $30(6-87)$ \\
\hline After 1998 & 14 & $|7,83|$ & $79(43-132)$ \\
\hline
\end{tabular}

Note: Rate of burn injury during LTOT per 100,000 person-years in Sweden.

Abbreviations: LTOT, long-term oxygen therapy; Cl, confidence interval; WHO, World Health Organization; COPD, chronic obstructive pulmonary disease.

Two deaths were related to burn injury during LTOT. Burn injury was the immediate cause of death in one patient and the underlying cause in another patient.

\section{Discussion}

In this first prospective, population-based study, the incidence of burn injury requiring health care while on LTOT was low with a mean rate of 61 events per 100,000 person-years on oxygen therapy.

The rate of burn injury did not differ due to smoking status at baseline but tended to be higher in women than in men and patients starting LTOT after 1998. Interestingly, this sex ratio is the complete opposite to the common ratio regarding burn injuries in Sweden and other developed countries. In hospitalized burns in Sweden, the ratio is 2.23 males for each female (69\% male and $31 \%$ female). ${ }^{21}$ Women of the studied age group might be more likely to do household activities than men, including cooking, which could partly explain the increased risk of burns observed among women. Another possible explanation is the fact that the need for LTOT is increasing more rapidly among women than among men. ${ }^{4}$

Despite the risk of burn injuries being low, there were two burn-related deaths ( $12 \%$ of all burn injuries). Patients with burn injuries secondary to smoking while on LTOT differ from other burns patients and, as they are older, have higher rates of inhalation injury and longer periods of hospitalization. ${ }^{11,16}$ The prevention of this type of injury would improve the safety of the patients and those in their vicinity.

The low incidence of burn injury could be explained by several factors: 1) LTOT in Sweden is prescribed mainly by specialists in respiratory medicine or physicians with special training in COPD and respiratory failure, either chest physicians or internists. Prescription and follow-up of LTOT are financed by the Swedish government and cannot be purchased privately outside medical care. Over $85 \%$ of LTOT patients in Sweden have severe hypoxemia (arterial partial pressure of oxygen $<7.4 \mathrm{kPa}$ [55.5 $\mathrm{mmHg}$ ] breathing air) when LTOT was initiated. ${ }^{22}$ Inappropriate prescription to patients not meeting the LTOT criteria might increase the risk of fire and burn injury; ${ }^{13}$ ) when a patient is identified as eligible for LTOT by the physician, contact is established with a local specialized oxygen nurse who handles the practical aspects and follow-up of therapy. ${ }^{23}$ Home conditions are checked, including the presence of risk factors for fire, including smoking, gas stove, and open fireplaces. The occupational therapist helps with home adaptation as needed; and a further reason is that 3) active smoking is an established contraindication for LTOT in Sweden. In most smokers, LTOT is withheld or terminated after reasonable harm reduction techniques have failed. Patients are often informed at the initiation of LTOT that the treatment may be discontinued if smoking is resumed. For patients relapsing into smoking while on LTOT, the oxygen nurse should inform the treating physician, which most often will result in a temporary break in LTOT and the introduction of an intensified smoking cessation program.

In the current study, only $2 \%$ of patients were smokers when starting LTOT compared to $21 \%$ in Denmark and $14 \%$ in Scotland. ${ }^{24,25}$ The rate of smoking during LTOT has been reported as between 14\% (despite smoking being an absolute contraindication in that study) and $26 \%$ of patients. ${ }^{10,26}$ A survey of Canadian pulmonologists found that $41 \%$ would prescribe LTOT to active smokers. ${ }^{27}$ 
The issue of tobacco smoking and home oxygen is full of controversy with ethical arguments of discrimination against smokers and the conflict between the patient's right to smoke and the risk of harm to self and others. This ethical dilemma was reviewed by Lacasse who suggested not prescribing oxygen to active smokers who fail to adhere to instructions and reevaluating patients discharged with a home oxygen prescription after hospitalization because a third of such patients no longer meet the requirements for home oxygen. ${ }^{28,29}$ Furthermore, the Veterans Health Administration in the USA addressed the following recommendations regarding the prescription of LTOT to active smokers: clinicians should familiarize themselves with the risks and benefits of LTOT; should inform their patients of the risks and benefits without exaggerating the risk associated with smoking; avoid undue coercion inherent in the clinician's ability to withdraw LTOT; reduce the risk to the greatest degree possible; and consider termination of LTOT in very extreme cases and in consultation with a multidisciplinary committee. ${ }^{30}$

The prevailing perspective in Sweden is that the risk of burns during LTOT extends to persons other than the patient. Family, home care providers, informal caregivers, and other persons such as neighbors could all be harmed in a fire. ${ }^{22}$ While the probability of fire is low, the potential degree of harm is great, which magnifies the subjective sense of risk. The present study extends the knowledge that the incidence of burn injury requiring health care seems to be low during LTOT in Sweden given the relatively strict smoking contraindications and practices. Comparative longitudinal studies of the risk of burn injury in settings with permissive smoking during LTOT are needed.

\section{Strengths and limitations}

The strengths of the current study include its national, longitudinal, population-based design with high coverage including all hospitalizations since 1987 and the National Causes of Death Register. Burn injuries requiring medical care were identified using a sensitive screening of all diagnoses, external causes, procedural codes, and causes of death, and were ascertained by a specialist in burn injury care, cross-validated by a second author; the process was blinded for all patient covariates.

There were several possible limitations. The incidence of burn injury pertains to events causing hospitalization or specialist consultation. However, the analysis included all registered diagnoses in Sweden since 1987 on diagnoses (primary and secondary), surgery (including plastic day surgery), and hospitalizations. We had limited data on the characteristics and circumstances surrounding the burn injuries of which some might have been unrelated to the LTOT. The excess risk of burn injury during LTOT could be explored by subtracting the underlying risk of burn injuries in the matched general population. The validity of the burn injuries was however individually ascertained by a specialist review, which was not possible for the general population. Smoking status was available at baseline only. We compared the incidence of burn injury between eversmokers and never-smokers as smoking relapse is probably limited to people in the former group. Data on the patients' living conditions were limited as were the extent and severity of burn injuries. Events were too few to allow multivariate analysis wherefore possible risk factors were explored using stratified analysis. Given the population-based national data, the incidence rates are likely to reflect current clinical practice and enable comparisons with other settings internationally.

Importantly, the low incidence of burn injuries cannot be interpreted as smoking being safe and should be permitted during LTOT. On the contrary, it shows that the risk of serious burn injury is low given current structured and relatively strict regulations and follow-up of LTOT in Sweden. While the present study provides novel risk data for comparison, the relative risk of burn injury associated with active smoking during LTOT needs further evaluation.

\section{Conclusion}

The rate of burn injuries in patients with LTOT seems to be low in Sweden. The strict requirements in Sweden for smoking cessation before LTOT initiation may contribute to this finding.

\section{Acknowledgments}

The authors thank associate professor Kerstin Ström, founder of the Swedevox register and a constant inspiration, and all the doctors and nurses who cared for the patients.

\section{Disclosure}

ME was supported by unrestricted grants from the Swedish Society of Medicine, the Swedish Respiratory Society, the Scientific Committee of Blekinge County Council, the Wera and Emil Cornell Foundation, and the Swedish Heart-Lung Foundation. HAT was supported by unrestricted grants from the Swedish Society of Medicine. FH was supported by unrestricted grants from the Swedish Society of Medicine and local funds from Uppsala County Council (ALF project). The authors report no other conflicts of interest in this work. 


\section{References}

1. Nocturnal Oxygen Therapy Trial Group. Continuous or nocturnal oxygen therapy in hypoxemic chronic obstructive lung disease: a clinical trial. Ann Intern Med. 1980;93(3):391-398.

2. Hardinge M, Annandale J, Bourne S, et al. British Thoracic Society guidelines for home oxygen use in adults. Thorax. 2015;70(1):1-43.

3. Christopher KL, Porte P. Long term oxygen therapy. Chest. 2011;139(2): 430-434.

4. Franklin KA, Gustafson T, Ranstam J, Ström K. Survival and future need of long-term oxygen therapy for chronic obstructive pulmonary disease-gender differences. Respir Med. 2007;101(7):1506-1511.

5. American Thoracic Society/European Respiratory Society. Standards for the diagnosis and treatment of patients with chronic obstructive pulmonary disease. Eur Respir J. 2004;23:932-946.

6. Ekström M, Franklin KA, Ström KE. Increased relative mortality in women with severe oxygen-dependent COPD. Chest. 2010;137(1): $31-36$.

7. Anthoninsen NR, Skeans MA, Wise RA, Manfreda J, Kanner RE, Connett JE. The effects of a smoking cessation intervention on 14.5 year mortality: a randomized clinical trial. Ann Intern Med. 2005;142(4): 233-239.

8. Chang TT, Lipinski CA, Sherman HF. A hazard of home oxygen therapy. J Burn Care Rehabil. 2001;22(1):71-74.

9. Ringbaek TJ, Lange P. The impact of the Danish Oxygen Register on adherence to guidelines for long-term oxygen therapy in COPD patients. Respir Med. 2006;100(2):218-225.

10. Verduri A, Ballerin L, Simoni M, et al. Poor adherence to guidelines for long-term oxygen therapy (LTOT) in two Italian university hospitals. Intern Emerg Med. 2014;9(3):319-324.

11. Sharma G, Meena R, Goodwin JS, Zhang W, Kuo YF, Duarte AG. Burn injury associated with home oxygen use in patients with chronic obstructive pulmonary disease. Mayo Clin Proc. 2015;90(4):492-499.

12. Meuhlberg T, Smith MA, Wong L. Domiciliary oxygen and smoking: an explosive combination. Burns. 1998;24(7):658-660.

13. Robb BW, Hungness ES, Hershko DD, Warden GD, Kagan RJ. Home oxygen therapy: adjunct or risk factor? J Burn Care Rehabil. 2003; 24(6):403-406.

14. Edelman DA, Maleyko-Jacobs S, White MT, Lucas CE, Ledgerwood AM. Smoking and home oxygen therapy a preventable public health hazard. J Burn Care Res. 2008;29(1):119-122.

15. Wendling T, Pelletier A. Fatal fires associated with smoking during long-term oxygen therapy - Maine, Massachusetts, New Hampshire and Oklahoma 2000-2007. MMWR Morb Mortal Wkly Rep. 2008; 57(31):852-854.
16. Murabit A, Tredget EE. Review of burn injuries secondary to home oxygen. J Burn Care Res. 2012;33(2):212-217.

17. Strom K, Boe J. A national register for long-term oxygen therapy in chronic hypoxia: preliminary results. Eur Respir J. 1988;1(10):952-958.

18. Löfdahl K, Gustafson T, Franklin KA, Ström K. Need of integrated guidelines for home oxygen therapy. Lakartidningen. 2007;104(24-25): 1902-1904

19. Sørensen JB, Klee M, Palshof T, Hansen HH. Performance status assessment in cancer patients. An inter-observer variability study. Br J Cancer. 1993;67(4):773-775.

20. Ludvigsson JF, Andersson E, Ekbom A, et al. External review and validation of the Swedish national inpatient register. BMC Public Health. 2011;11:450.

21. Åkerlund E, Huss F, Sjöberg F. Burns in Sweden: an analysis of 24,538 cases during 1987-2004. Burns. 2007;33(1):31-36.

22. Gustafson T, Löfdahl K, Ström K. A model of quality assessment in patients on long-term oxygen therapy. Respir Med. 2009;103(2): 209-215.

23. Swedevox annual report 2012-2013. Available from: http://www.ucr. uu.se/Swedevox/. Accessed April 15, 2015.

24. Ringbaek T, Lange P, Viskum K. Geographic variation in long-term oxygen therapy in Denmark: factors related to adherence to guidelines for long-term oxygen therapy. Chest. 2001;119(6):1711-1716.

25. Morrison D, Skwarski K, MacNee W. Review of the prescription of domiciliary long-term oxygen therapy in Scotland. Thorax. 1995;50(12): 1103-1105.

26. Katsenos S, Froudarakis ME, Charisis A, Vassiliou MP, Constantopoulos SH. Long-term oxygen therapy in Ioannina. Respiration. 2004;71(6):619-624.

27. Lacasse Y, Series F, Martin S, Maltais F. Nocturnal oxygen therapy in patients with chronic obstructive pulmonary disease: a survey of Canadian respirologists. Can Respir J. 2007;14(6):343-348.

28. Lacasse Y, LaForge J, Maltais F. Got a match? Home oxygen therapy in current smokers. Thorax. 2006;61(5):374-375.

29. Levi-Valensi P, Weitzenblum E, Pedinielli JL, Racineux JL, Duwoos H. Three-month follow-up of arterial blood gas determinations in candidates for long-term oxygen therapy: a multicentric study. Am Rev Respir Dis. 1986;133(4):547-551.

30. Veterans Health Administration National Center for Ethics in Health Care. Ethical considerations that arise when a home care patient on long term oxygen therapy continues to smoke. Available from: http:// www.ethics.va.gov//nec_report_20100301. Accessed July 8, 2014.
International Journal of COPD

\section{Publish your work in this journal}

The International Journal of COPD is an international, peer-reviewed journal of therapeutics and pharmacology focusing on concise rapid reporting of clinical studies and reviews in COPD. Special focus is given to the pathophysiological processes underlying the disease, intervention programs, patient focused education, and self management protocols.

\section{Dovepress}

This journal is indexed on PubMed Central, MedLine and CAS. The manuscript management system is completely online and includes a very quick and fair peer-review system, which is all easy to use. Visit http://www.dovepress.com/testimonials.php to read real quotes from published authors. 